\title{
Analyzing the Relationship between Employee Empowerment and Organizational Success in Sarcheshmeh Copper Complex
}

\author{
Mandana Bakhtiari ${ }^{1}$, Yousef Ahmadi ${ }^{2}$ andAli Sarchami ${ }^{3}$ \\ ${ }^{1}$ Master of Human Resource Management, Management Faculty, Islamic Azad University of Sirjan \\ Man_gs2012@yahoo.com \\ ${ }^{2}$ Faculty member of Management major, Islamic Azad University of Sirjan \\ Bolandasseman5385@yahoo.com \\ ${ }^{3}$ Faculty member of economic major, Islamic Azad University of Sirjan \\ Alisarchami@yahoo.com \\ Corresponding Author Email: Man_gs2012@yahoo.com
}

\section{Article history:}

Received date: 28 January, 2019

Review date: 07 September 2019

Accepted date:06 November 2019

\section{Keywords:}

empowerment of staff, organizational success, Sarcheshmeh Copper Complex

\begin{abstract}
The purpose of this study is analyzing the relationship between employee empowerment and organizational success in Sarcheshmeh Copper Complex. This is an applied research and the nature and method is descriptive and correlational. The Statistical population was all employees of Sarcheshmeh Copper Complex (2628 persons). The sample size is based on Morgan table is 335 people who were selected using stratified random selection. In order to measure empowerment, the questionnaire based on aspects of competence, sense of meaning, sense of effectiveness, autonomy and trust in colleagues have been used and organizational success was measured using a questionnaire based on the speed of service, flexibility in service delivery, integrity and innovation in the delivery of service. Reliability of empowerment and organizational success respectively was 0.939 and 0.950. To examine the hypothesis the correlation and regression analysis were used. The results showed that there is a direct and significant relationship between empower employees and its dimensions with organizational success in Sarcheshmeh Copper Complex and dimensions of empowerment are predictive for the success of the organization.
\end{abstract}

Please cite this article as: Bakhtiari Mandana, Ahmadi Yousef, Sarchami Ali. 2019. Analyzing the Relationship between Employee Empowerment and Organizational Success in Sarcheshmeh Copper Complex. SRPH Journal of Applied Management and Agile Organisation Volume 1, Number 1: (1-8), 2019

\section{Introduction:}

Human resources are the most original, largest and most valuable asset of an organization and a country (Vakili, 2011: 3). If there is no creative person in the organization, knowledge workers, opportunity recognition and explanation of benefit, we will lose a lot of opportunities and situations. (Amir Mahani, 2012: 8). Empowerment is a concept that can meet the interests and the sense of ownership and pride in their staff, the ideal thing for many organizations and their employees. Empowerment is one of the most promising concepts in the business world that has received less attention. (Vakili, 2011: 3). Empowering provides potential for exploitation of the source of the ability of humans to use it completely. Empower employees benefit themselves and their organizations. More jobs and their working life are feeling intended and there engaging is directly becomes to the continuous improvement of systems and processes work. (Vatani, 2010: 38). The benefits of empowering staff and managers will be passive. Foster a sense of empowerment and self-sufficiency, by providing the freedom for employees, they will have the opportunity to improve their abilities and skills and provide grounds for its effectiveness. Sarcheshmeh Copper Complex, is one of the leading industries in the competitive global market and is not an exception and empowerment and upgrade and update the knowledge of their staff is considered because by developing motivated and capable employees, it will allow managers to respond faster and better the dynamics of the competitive environment and will be followed by organization success. One of the main challenges of the present era 
managers is inefficient use of intellectual resources, intellectual potential and available human resources. In most organizations the usage of staff strength will not be an efficient and their managers are not able to use their potential. In other words, employees have the power of creativity, imagination and are more active, but in the enterprise environment these features not exploit to be desired for some reasons. Scholars of change management and organizational improvement, have introduced employee empowerment as a strategy affecting the performance and improvement of human resources and believe that empowerment is one of the important new attitudes which today is used by organizations and in fact is a response to the urgent need to respond to the needs of modern management transformation (Kinlaw, 2004: 6). Empowerment is the healthiest way for sharing power; with this method, confidence, energy, pride, commitment and self-reliance is created in individuals and a sense of participation in the organization will increase and it will be followed by organizational success. (Dehnavi, 2010: 37). Empowerment is considered as one of new issues in human resource development. However, due to a variety of research and studies in this field has extensive literature (Littrell, 2007: 87). In particular, the different approaches that have been studied (Robbins et al., 2002: 419). Although variations in the empowerment literature enhances its content, but it is the cause of the lack of integrity and providing a comprehensive model of empowerment (Littrell, 2007: 88). Four overall view of empowerment are; rational perspective, motivational perspective, the high motivational perspective and systematic perspective (Mirzaee Aharnjani, 1998: 60). Bowen and Laver (1992) know empowering as a front line of staff to take part in the four elements of information, knowledge, bonuses and power (Amirkhni, 2008: 44). Blanchard et al. (1996) have identified three necessary steps for the implementation of empowerment: sharing staff at information, substitution groups rather than traditional hierarchy and organizational structure design (Iranzhad Parizi, 2008: 18). According to Conger \& Kanungo (1998) empowerment is rooted in the need for motivation of individuals. Any strategy or action that could require employees to boost self-empowerment will lead to empowerment (Conger \& Kanungo, 1998: 474). According to this approach, empowerment means taking risks, grow, change, and trust in employees and their failures (Amirkhni, 2008: 45). Thomas \& Velthouse (1990) argue that empowerment is increasing intrinsic motivation of job which in a series of four reflects the attitude of individual on his job role. The four components to Thomas \& Velthouse (1990) include: impact, competence, meaningfulness and selection (Heidarpour, 2010: 25). Spritzer (1992), based on the work of Thomas \& Velthouse focused on the extension of the empowerment term. He used the variables of competence, meaningfulness and selection to operationalize the definition and measurement of psychological empowerment in the organization. After extensive review of the literature on empowerment he presented four aspects of psychological empowerment: a sense of meaningfulness, sense of competence, a sense of determination and sense of the impact (Heidarpour, 2010: 25). In this study, Mishra model (1999) was used. This model is the most comprehensive model of empowerment. The psychological empowerment aspects include: a sense of competence, a sense of autonomy (choice), a sense of meaningfulness (being valuable), a sense of effectiveness and sense of confidence in colleagues (Abdullahi, 2005: 41). Some experts suggest that the success of an organization have the following features:

1- The flexibility ability to respond to changing environment

2- The relative stability and integrity which its employees will feel safe enough (Goudarzvand Chegini, 2007: 123).

Due to rapid changes and accelerating human knowledge, everything is changing rapidly. The organization as an open system for their survival, interact with the environment and are responding to environmental changes which are needed. Since human resources are the most important factor and centered organizations, equipping and preparing the resources for dealing with changes, of particular importance, and all organizations of any type of mission to be the greatest investment of time and plan allocate to human development in various aspects. Many organizations implement empowerment programs to recognize solution to this problem and have tried to provide necessary background for education and empowerment (Paktinat and Fathizadeh, 2008: 33). Not using enough intellectual resources and potential of existing human resources is one of the most important challenges facing managers today. People can have more creativity and activity, but for some reason does not use this feature in the organizational environment (Amir Mahani, 2012: 14). Environmental changes and increasing global competition, took managers focuses on the topic of 
employee empowerment. Because organizations with empowered, committed, skilled and motivated employees, are able better to adapt to changes and compete. Empowerment is the healthiest way for sharing employees with power. In this way, confidence, energy, pride, commitment and self-reliance are created in the people and will increase a sense of participation in the organization consumption, improving performance (Paktinat and Fathizadeh, 2008: 35). Empowering individuals is a reason of organizations to achieve their goals quickly and without waste of resources. Empowerment of individuals makes them believe that organizations and jobs belong to their own and apply maximum power in order to achieve the objectives of the organization. In this way the organization's staff will be at the service of higher goals. Considering the many benefits that will follow by empowering employees for organizations it is necessary to identify ways to achieve this goal (Amir Mahani, 2012: 14). According to the above-mentioned, it is necessary to investigate the relationship between employee empowerment and organizational success of the Sarcheshmeh Copper Complex. If there is any such relationship to increase organizational success due to employee empowerment, it should be put in their proper place and take an important step toward organizational success. The purpose of this study is analyzing the relationship between employee empowerment and organizational success in Sarcheshmeh Copper Complex.

1- Mirfakhredini (2012) in a study entitled "the effects of job stress on religious attitudes and organizational success on fuzzy neural network approach (Case Study: public and private hospitals of Tehran province" studied. In this study, while recognizing human factors affecting the success of an organization (religious attitude and job stress) was possible to design organizational success prediction model and analyzed the type and how human factors affecting organizational success. The research objective of this study is placed in the category of applied research. It is including a clear definition of the problem, the scientific history of the topic and the approach or solution which is proposed. The introduction should be comprehensible to researchers of most scientific majors.

2- Faraji Sabokbar et al (2012) have done a study on "the mechanism of the effect of information technology on women's empowerment in Gharnabad village of Golestan Province ". In this study, using the survey method, the number of 38 IT users and 25 non-users, patients (control group) were selected by stratified random sampling. The women users of information technology in terms of land use were classified into seven levels.

3- Qudah and Melhem (2011) in a study analyzed the effect of information, information systems and information technology to empower their employees. 120 employees participated in the survey. The collected data was analyzed using correlation and regression. The results show that information systems, information technology and information generally have a significant impact on empowering front-line employees.

4- Azman Esmail et al (2009) have done a research entitled empowering the role of mediator between transformational leadership and quality of service. The researchers argue, this study aimed to measure the effect of transformational leadership qualities and empowerment in the quality of the service. Transformational leadership has two outstanding features: intellectual stimulation and individual thinking. They believe that recent studies in this field show that the effect of leadership qualities in job performance is indirectly influenced by empowerment. The nature of this relationship is interesting but few studies shows that the effect has mediated aspects of empowerment in leadership management model. The research data has been collected from 110 questionnaires completed by employees at a place called Sarawak in Malaysia.

\section{Methodology:}

In this study, it was tried to use correct and logical approach often used by researchers and experts to have the characteristics of a scientific study. The research method is descriptive. This research in term of study purpose is applied and in term of method is descriptive and analytical. The required information has been collected through questionnaire. The statistical population is consisted of the research staff of Sarcheshmeh Copper Complex consisting of 2628 people. The statistical population is made of female and male employees with educational degrees of; diploma, associate degree, bachelors, masters and higher and in term of organizational position have been formed in all corporate positions including: Chairman, Director, experts, officials, officers, employees and various business records. 
To obtain a sample according to Morgan table because of the limitations of statistical population, a sample size of 335 people were selected.

In this study, each of Sarcheshmeh Copper Complex units considered as a class and on each class, the proportion of people working in that unit, the sample size is selected using simple random sampling. It means the size of each unit is clear and then based on the number of people needed to meet the sample size from the list were selected based on the number of personnel of the unit randomly. The correlation and regression analysis using SPSS software is used to analyze and describe the data and assumptions of frequency distribution and descriptive statistics. Also for analyzing independent t- tests (two samples) and one-way analysis of variance (ANOVA) this software was used.

\section{Research findings:}

Frequency distribution of subjects by gender:

Among the 328 understudy people, 287 (87.5\%) were men and 41 (12.5\%) were female.

Frequency distribution of subjects by marital status:

Among the 328 understudy people, 285 (86.9\%) were married and 43 (13.1\%) were single.

Frequency distribution of subjects by educational degree:

Among the 328 understudy people, 20 (1.6 percent) had diploma, 78 (23.8 percent) had associate degree, 174 (0.53 percent) had bachelor, 51 (15.5 percent) had master and 5 (6.1\%) had Ph.D.

Frequency distribution of subjects by work experience:

Among the 328 understudy people $57(17.4 \%)$ had between 6 to 10 years, $82(25 \%)$ had between 11 and 15 years, $68(20.7 \%)$ had between 16 to 20 years, $66(20.1 \%)$ had between 21 and 25 years and $55(16.8 \%)$ had 26 years or more work experience.

\section{Data analysis:}

The main hypothesis: there is a significant relationship between staff empowerment and organizational success in Sarcheshmeh Copper Complex.

$\mathbf{H}_{0}$ : there is no significant relationship between staff empowerment and organizational success in Sarcheshmeh Copper Complex.

$\mathbf{H}_{1}$ : there is a significant relationship between staff empowerment and organizational success in Sarcheshmeh Copper Complex.

Pearson correlation coefficient is used to study the relationship between employee empowerment and organizational success (quantitative data and normal). The results of this test are presented in the table.

Table 1: the correlation coefficient between employee empowerment and organizational success

\begin{tabular}{|c|c|c|c|c|c|c|}
\hline \multirow{2}{*}{ variable } & \multirow{2}{*}{ Relation type } & \multirow{2}{*}{ Relationship } & \multicolumn{3}{|c|}{ Organizational success } & \multirow[t]{2}{*}{$\mathrm{R}^{2}$} \\
\hline & & & number & significance & Pearson correlation coefficient & \\
\hline empowerment & direct & It has & 328 & ${ }^{*}<0 / 001$ & $0 / 654$ & $0 / 416$ \\
\hline
\end{tabular}

The results of Pearson correlation coefficient test showed that there is a significant relationship between employee empowerment and organizational success (Significance level is less than 0.05). This relationship is direct and has strong levels.

First alternative hypothesis: there is a significant relationship between the sense of competence and organizational success in Sarcheshmeh Copper Complex.

$\mathbf{H}_{\mathbf{0}}$ : there is no significant relationship between the sense of competence and organizational success in Sarcheshmeh Copper Complex.

$\mathbf{H}_{\mathbf{1}}$ : there is a significant relationship between the sense of competence and organizational success in Sarcheshmeh Copper Complex.

Pearson correlation coefficient is used to study the relationship between sense of competence and organizational success (quantitative data and normal). The results of this test are presented in the table. 
Table 2: the correlation coefficient between sense of competence and organizational success

\begin{tabular}{lllllll}
\hline \multirow{2}{*}{ variable } & \multirow{2}{*}{ Relation type } & Relationship & \multicolumn{3}{l}{ Organizational success } & $\mathrm{R}^{2}$ \\
\cline { 3 - 5 } & & & number & significance & Pearson correlation coefficient \\
\hline sense of competence & direct & It has & 328 & ${ }^{*}<0 / 001$ & 0.354 & 0.126 \\
\hline
\end{tabular}

The results of Pearson correlation coefficient test showed that there is a significant relationship between sense of competence and organizational success (Significance level is less than 0.05). This relationship is direct and is at weak level.

Second alternative hypothesis: there is a significant relationship between the sense of effectiveness and organizational success in Sarcheshmeh Copper Complex.

$\mathbf{H}_{\mathbf{0}}$ : there is no significant relationship between the sense of effectiveness and organizational success in Sarcheshmeh Copper Complex.

$\mathbf{H}_{1}$ : there is a significant relationship between the sense of effectiveness and organizational success in Sarcheshmeh Copper Complex.

Pearson correlation coefficient is used to study the relationship between sense of competence and organizational success (quantitative data and normal). The results of this test are presented in the table.

Table 3: the correlation coefficient between sense of effectiveness and organizational success

\begin{tabular}{|c|c|c|c|c|c|}
\hline \multirow{2}{*}{ variable } & \multirow{2}{*}{ Relation type } & \multirow{2}{*}{ Relationship } & \multicolumn{2}{|l|}{ Organizational success } & \multirow[t]{2}{*}{$\mathrm{R}^{2}$} \\
\hline & & & number significance & Pearson correlation coefficient & \\
\hline sense of effectiveness & direct & It has & ${ }^{*}<0 / 001$ & 0.479 & 0.229 \\
\hline
\end{tabular}

The results of Pearson correlation coefficient test showed that there is a significant relationship between sense of effectiveness and organizational success (Significance level is less than 0.05). This relationship is direct and is at average level.

Third alternative hypothesis: there is a significant relationship between the sense of meaningfulness and organizational success in Sarcheshmeh Copper Complex.

$\mathbf{H}_{\mathbf{0}}$ : there is no significant relationship between the sense of meaningfulness and organizational success in Sarcheshmeh Copper Complex.

$\mathbf{H}_{1}$ : there is a significant relationship between the sense of meaningfulness and organizational success in Sarcheshmeh Copper Complex.

Pearson correlation coefficient is used to study the relationship between sense of meaningfulness and organizational success (quantitative data and normal). The results of this test are presented in the table.

Table 4: the correlation coefficient between sense of meaningfulness and organizational success

\begin{tabular}{|c|c|c|c|c|c|c|c|}
\hline \multirow{2}{*}{ variable } & \multirow{2}{*}{$\begin{array}{l}\text { Relation } \\
\text { type }\end{array}$} & \multirow{2}{*}{ Relationship } & \multicolumn{4}{|c|}{ Organizational success } & \multirow[t]{2}{*}{$\mathrm{R}^{2}$} \\
\hline & & & number & significance & $\begin{array}{l}\text { Pearson } \\
\text { coefficient }\end{array}$ & correlation & \\
\hline $\begin{array}{l}\text { sense of } \\
\text { meaningfulness }\end{array}$ & direct & It has & 328 & ${ }^{*}<0 / 001$ & 0.410 & & 0.168 \\
\hline
\end{tabular}

The results of Pearson correlation coefficient test showed that there is a significant relationship between sense of meaningfulness and organizational success (Significance level is less than 0.05). This relationship is direct and is at average level.

Fourth alternative hypothesis: there is a significant relationship between the sense of autonomy and organizational success in Sarcheshmeh Copper Complex. 
$\mathbf{H}_{\mathbf{0}}$ : there is no significant relationship between the sense of autonomy and organizational success in Sarcheshmeh Copper Complex.

$\mathbf{H}_{1}$ : there is a significant relationship between the sense of meaningfulness and organizational success in Sarcheshmeh Copper Complex.

Pearson correlation coefficient is used to study the relationship between sense of autonomy and organizational success (quantitative data and normal). The results of this test are presented in the table.

Table 5: the correlation coefficient between sense of autonomy and organizational success

\begin{tabular}{|c|c|c|c|c|c|}
\hline \multirow{2}{*}{ variable } & \multirow{2}{*}{ Relation type } & \multirow{2}{*}{ Relationship } & \multicolumn{2}{|l|}{ Organizational success } & \multirow[t]{2}{*}{$\mathrm{R}^{2}$} \\
\hline & & & significance & Pearson correlation coefficient & \\
\hline sense of autonomy & direct & It has & ${ }^{*}<0 / 001$ & 0.635 & 0.403 \\
\hline
\end{tabular}

The results of Pearson correlation coefficient test showed that there is a significant relationship between sense of autonomy and organizational success (Significance level is less than 0.05). This relationship is direct and is at average level.

Fifth alternative hypothesis: there is a significant relationship between the sense of trusting colleagues and organizational success in Sarcheshmeh Copper Complex.

$\mathbf{H}_{\mathbf{0}}$ : there is no significant relationship between the sense of trusting colleagues and organizational success in Sarcheshmeh Copper Complex.

$\mathbf{H}_{1}$ : there is a significant relationship between the sense of trusting colleagues and organizational success in Sarcheshmeh Copper Complex.

Pearson correlation coefficient is used to study the relationship between sense of trusting colleagues and organizational success (quantitative data and normal). The results of this test are presented in the table.

Table 6: the correlation coefficient between sense of trusting colleagues and organizational success

\begin{tabular}{|c|c|c|c|c|c|c|c|}
\hline \multirow[b]{2}{*}{ variable } & \multirow{2}{*}{$\begin{array}{l}\text { Relation } \\
\text { type }\end{array}$} & \multirow[b]{2}{*}{ Relationship } & \multicolumn{4}{|c|}{ Organizational success } & \multirow[t]{2}{*}{$\mathrm{R}^{2}$} \\
\hline & & & number & significance & $\begin{array}{l}\text { Pearson } \\
\text { coefficient }\end{array}$ & correlation & \\
\hline $\begin{array}{l}\text { sense of } \\
\text { colleagues }\end{array}$ & direct & It has & 328 & ${ }^{*}<0 / 001$ & 0.651 & & 0.424 \\
\hline
\end{tabular}

The results of Pearson correlation coefficient test showed that there is a significant relationship between sense of trusting colleagues and organizational success (Significance level is less than 0.05). This relationship is direct and is at strong level.

Discussion and Conclusion:

The main hypothesis: there is a significant relationship between staff empowerment and organizational success in Sarcheshmeh Copper Complex.

The results of Pearson correlation coefficient test showed that there is a significant relationship between staff empowerment and organizational success (Significance level is less than 0.05). This relationship is direct and is at strong level. Based on regression analysis, empowerment directly predict the organizational success and it has increasing effect $(\mathrm{p} \leq 0.01$ and Beta $=0.645)$ and according to adjusted coefficient of determination $\left(\mathrm{R}_{\text {adj }}^{2}\right) 42 \%$ of changes in organizational success by empowering is explained. The regression model is as follows:

Organizational success $=0.645 \times$ employees' empowerment

First alternative hypothesis: there is a significant relationship between the sense of competence and organizational success in Sarcheshmeh Copper Complex.

The results of Pearson correlation coefficient test showed that there is a significant relationship between sense of competence and organizational success (Significance level is less than 0.05). This relationship is direct and is at weak level. Based on regression analysis, sense of competence directly predict the 
organizational success and it has increasing effect $(\mathrm{p} \leq 0.01$ and Beta $=0.354)$ and according to adjusted coefficient of determination $\left(\mathrm{R}_{\text {adj }}^{2}\right) 12 \%$ of changes in organizational success by sense of competence is explained. The regression model is as follows:

Organizational success $=0.354 \times$ sense of competence

Second alternative hypothesis: there is a significant relationship between the sense of effectiveness and organizational success in Sarcheshmeh Copper Complex.

The results of Pearson correlation coefficient test showed that there is a significant relationship between sense of effectiveness and organizational success (Significance level is less than 0.05). This relationship is direct and is at average level. Based on regression analysis, sense of effectiveness directly predict the organizational success and it has increasing effect $(\mathrm{p} \leq 0.01$ and Beta $=0.479)$ and according to adjusted coefficient of determination $\left(\mathrm{R}^{2}\right.$ adj $) 23 \%$ of changes in organizational success by sense of effectiveness is explained. The regression model is as follows:

Organizational success $=0.479 \times$ sense of effectiveness

Third alternative hypothesis: there is a significant relationship between the sense of meaningfulness and organizational success in Sarcheshmeh Copper Complex.

The results of Pearson correlation coefficient test showed that there is a significant relationship between sense of meaningfulness and organizational success (Significance level is less than 0.05). This relationship is direct and is at average level. Based on regression analysis, sense of meaningfulness directly predict the organizational success and it has increasing effect $(\mathrm{p} \leq 0.01$ and $B e t a=0.410)$ and according to adjusted coefficient of determination $\left(\mathrm{R}^{2}{ }_{\text {adj }}\right) 17 \%$ of changes in organizational success by sense of meaningfulness is explained. The regression model is as follows:

Organizational success $=0.410 \times$ sense of meaningfulness

Fourth alternative hypothesis: there is a significant relationship between the sense of autonomy and organizational success in Sarcheshmeh Copper Complex.

The results of Pearson correlation coefficient test showed that there is a significant relationship between sense of meaningfulness and organizational success (Significance level is less than 0.05). This relationship is direct and is at average level. Based on regression analysis, sense of autonomy directly predict the organizational success and it has increasing effect $(\mathrm{p} \leq 0.01$ and $B e t a=0.635)$ and according to adjusted coefficient of determination $\left(\mathrm{R}^{2}{ }_{\text {adj }}\right) 40 \%$ of changes in organizational success by sense of autonomy is explained. The regression model is as follows:

Organizational success $=0.635 \times$ sense of autonomy

Fifth alternative hypothesis: there is a significant relationship between the sense of trusting colleagues and organizational success in Sarcheshmeh Copper Complex.

The results of Pearson correlation coefficient test showed that there is a significant relationship between sense of trusting colleagues and organizational success (Significance level is less than 0.05). This relationship is direct and is at strong level. Based on regression analysis, sense of trusting colleagues directly predict the organizational success and it has increasing effect $(\mathrm{p} \leq 0.01$ and $B e t a=0.651)$ and according to adjusted coefficient of determination $\left(\mathrm{R}^{2}{ }_{\text {adj }}\right) 42 \%$ of changes in organizational success by sense of trusting colleagues is explained. The regression model is as follows:

Organizational success $=0.651 \times$ sense of trusting colleagues

\section{References:}

Amir Hossein Amir Khani, 2008, psychological empowerment, light peak, Issue 1, Pages 41-51.

Amir Mahani (2012) Evaluate the relationship between the use of information technology and employee empowerment in the mining company Gol Gohar, MA thesis, Islamic Azad University, Sirjan.

Azman Ismail, Nur Baizura Natasha Abidin and Rabaah Tudin., 2009, Prelationship Between Transformational Leadership, Empowerment And Followers' Performance: An Empirical Study in Malaysia, Revista Negotium, 13 (5) 5-22.

Bijan Abdollahi, 2005, Psychological empowerment of employees. Dimensions and validation based on structural equation modeling, Research and Planning in Higher Education, Volume 11, Issue: Pages. 63-37. 
Conger Jay A \& Kanungo Rabindra., 1998, The Empowerment Process: Integrating Theory and Practice, Academy of Management Review, Vol. 13, No. 3: 471-482.

Dennis Kynla, 1999, empowering human resources

Hasan Mirzaei Ahranjani, 1998, Analysis of factors affecting the work ethic and social discipline, work ethic Proceedings of the Second Summit to examine practical ways of governance and social discipline, Islamic Azad University

Hasanali Faraji Sabokbar, Morteza Nemati, Afshin Khaki, 2012, Investigating the mechanism of the effect of information technology on the empowerment of rural women (Case Study: Abad century village), Journal of Women in Development \& Politics (of women), No. 36, p. 125.

Iqbal Paktinat, Alireza Fathizadeh, 2008, empowering employees, necessity and strategies, Journal of Management, Issue 11.

Ismaeil Vakili, 2011, The relationship between empowerment of human resources and organizational performance (case study of bank branches welfare of Golestan province in 1388, MSc thesis, Islamic Azad University, Sirjan.

Khosrow Vatani, 2010, Factors Affecting the Human Resources Empowerment: A Case Study of the Planning and supervision of credit institutions and credit of the nation, Master Thesis, Islamic Azad University, North Tehran, Journal of Management, Vol. VII, No. 20, pp. 49-42.

Littrell, R. F., 2007, Influences on employee preferences for empowerment practices by the "ideal manager" in china. International Journal of Intercultural Relative ,31:87-110.

Mehrdad Gudarzvand Chegini, 2007, organizational structure based on the client's, management Monthly, Vol. 18, No. 123, p. 123.

Mirfakhordini Heyfar, 2012, The effect of job stress on religious attitudes and organizational success fuzzy neural network approach (Case Study: public and private hospitals of Tehran province), Journal of Health Administration; 15 (49): 39-46.

Qudah, Shaker., and Melhem, Yahya., 2011 Impact of Information and Information Technology on Empowerment of Employees Private School Sector in Northern Region in Jordan, Journal of Emerging Trends in Economics and Management Sciences (JETEMS) 2(1): 40-48

Reza Dehnavi, 2010, The relationship between organizational culture and organizational success Agriculture Organization, Master Thesis, University of Semnan.

Rezvan Heidaripour, 2010, to examine the relationship between organizational justice and empowerment (CASE STUDY: Sarcheshmeh Copper Complex staff), Master Thesis, University of Sistan and Baluchestan.

Robbins, T. L. \& Crino, M. D. \&Fredendall, L. D., 2002, An integrative model of the empowerment process, Human Resource Management Review, Vol. 12, pp 419-443.

Scheultz, D. Schoultz ES., 1998, The relationship between worker and enquipment. New Jersey: PrenticeHall, p 52.

Smith , jane., 2000, Empowering people.british library ,2 nd edition.p 16,26.

Thomas, K. W., \& Velthouse, B. A., 1990, Cognitive Elements of Empowerment: An "Interpretive" Model of Intrinsic Task Motivation, Academy of Management Journal, 15(4): 666-681. 